\title{
Development of a reference artificial sediment for chemical testing adapted to the MELA sediment contact assay
}

\author{
Le Bihanic Florane ${ }^{1}$, Perrichon Prescilla ${ }^{2}$, Landi Laure ${ }^{1}$, Clerandeau Christelle ${ }^{1}$, Le Menach Karyn ${ }^{1}$, \\ Budzinski Helene ${ }^{1}$, Cousin Xavier $^{2,3}$, Cachot Jerome ${ }^{1,}$
}

\footnotetext{
${ }^{1}$ University of Bordeaux, EPOC UMR CNRS 5805, 33405, avenue des Facultés, Talence Cedex, France

${ }^{2}$ IFREMER, Ecotoxicology laboratory, Place Gaby Coll, BP7, 17137, l'Houmeau, France

${ }^{3}$ INRA LPGP, Campus de Beaulieu, 35042, Rennes, France
}

*: Corresponding author : Jérôme Cachot, email address : j.cachot@epoc.u-bordeaux1.fr

\begin{abstract}
:
Most persistent organic pollutants, due to their hydrophobic properties, accumulate in aquatic sediments and represent a high risk for sediment quality. To assess the toxicity of hydrophobic pollutants, a novel approach was recently proposed as an alternative to replace, refine and reduce animal experimentation: the medaka embryo-larval sediment contact assay (MELAc). This assay is performed with Japanese medaka embryos incubated on a natural sediment spiked with the compound being tested. With the aim of improving this assay, our study developed a reference exposure protocol with an artificial sediment specifically designed to limit natural sediment composition uncertainties and preparation variability. The optimum composition of the new artificial sediment was tested using a model polycyclic aromatic hydrocarbon (PAH), fluoranthene. The sediment was then validated with two other model PAHs, benz[a]anthracene and benzo[a]pyrene. Various developmental end points were recorded, including survival, embryonic heartbeat, hatching delay, hatching success, larval biometry and abnormalities. The final artificial sediment composition was set at $2.5 \%$ dry weight (dw) Sphagnum peat, $5 \% \mathrm{dw}$ kaolin clay and $92.5 \%$ dw silica of $0.2-$ to $0.5-\mathrm{mm}$ grain size. In contrast with natural sediments, the chemical components of this artificial matrix are fully defined and readily identifiable. It is totally safe for fish embryos and presents relatively high sorption capacities for hydrophobic compounds. Studies with other hydrophobic and metallic contaminants and mixtures should be performed to further validate this artificial sediment.
\end{abstract}

Keywords: Artificial sediment ; Spiked sediment ; PAHs ; Japanese medaka embryos ; Embryotoxicity ; Teratogenicity 


\author{
Abbreviations: \\ PAH : Polycyclic Aromatic Hydrocarbon \\ fluo : fluoranthene \\ $\mathrm{BaA}$ : benz[a]anthracene \\ $\mathrm{BaP}$ : benzo[a]pyrene \\ dpf : days post fertilisation \\ MELA: Medaka Embryo-Larval Assay \\ dw : dry weight \\ ERS : Egg Rearing Solution \\ ELS : Early life stage
}

\title{
1. Introduction
}

Due to their high capacity to sorb and store contaminants, aquatic sediments are major sinks for persistent organic pollutants and thereby secondary sources of contamination for aquatic ecosystems (Harris et al. 1996). Sediments represent a real threat for all organisms living in contact with sediment or feeding from them. Organic compounds, such as polycyclic aromatic hydrocarbons (PAHs), are ubiquitous in the natural environment. Several studies have documented PAH concentrations of up to $50 \mu \mathrm{g} \mathrm{g}-1$ dry weight (dw) sediment in various affected aquatic ecosystems in Europe (Baumard et al. 1999; Benlahcen et al. 1997; Cachot et al. 2006). Multiexposure to PAHs can occur directly from the contaminated sediment, from the molecules adsorbed onto suspended particles or dissolved in the water column, or indirectly through consumption of benthic prey (Cailleaud et al. 2007; Mayer et al. 2007; ter Laak et al. 2009). The bioavailability of chemical compounds accumulated in sediments depends on several parameters, either physicochemical, such as molecule desorption organic matter content, overlying water properties and particle size, or external factors, such as dredging, storms, flood, tides and bioturbation (Roberts 2012; Cailleaud et al. 2009; Wölz et al. 2008; Sundberg et al. 2007).

The usefulness of fish early life stages (ELS) for chemical testing has been widely described in the literature (Belanger et al. 2010; Embry et al. 2010; Vicquelin et al. 2011), mainly because ELS are very sensitive to a large variety of chemicals (Lammer et al. 2009). Tests using fish embryos and eleutheroembryos (yolk-sac larvae) are not considered in vivo tests by EU regulations on the protection of animals used for scientific purposes (EC 2010). Fish ELS assays also fulfil the requirements of European $\mathrm{REACH}$ regulations on the reduction, refinement and replacement of animals for toxicity assessment of chemicals (EC 2006). More recently, sediment contact assays using ELS have been proposed as an alternative to classic ecotoxicity assays for chemical testing (Barjhoux et al. 2012; Vicquelin et al. 2011) and assessment of sediment toxicity (Hollert et 
al. 2003; Kosmehl et al. 2006; Rocha et al. 2011). These assays better reproduce the multiple sources of exposure

to benthic organisms via sediment, particle, and dissolved phases than water borne exposure.

Japanese medaka, Oryzias latipes, was selected primarily for its high sensitivity at early life stages to organic contaminants (Barjhoux et al. 2012; Cachot et al. 2007; Cachot et al. 2008; Farwell et al. 2006; Vicquelin et al. 2011) and its ability to bioaccumulate various classes of pollutants during the initial hours of development (McElroy et al. 2006; Hornung et al. 2004). In addition, Japanese medaka is easy to breed, and has a transparent chorion, making it possible to track each stage of embryonic development during exposure. Furthermore, the developmental biology of Japanese medaka has been accurately described in previous literature (Iwamatsu 2004). Lastly, the baseline mortality of embryos and sac fry are particularly low, at around $10 \%$ (Barjhoux et al. 2012; Vicquelin et al. 2011). A sediment contact version of the medaka embryo larval assay (MELAc) was recently developed for organic (Cachot et al. 2007; Vicquelin et al. 2011) and metallic pollutant testing (Barjhoux et al. 2012). Because natural sediment composition varies over time, its use in pollutant toxicity testing can be controversial (Bouloubassi et al. 2006). Since the behaviour of a spiked pollutant depends on sediment composition (Höss et al. 2010; Hsu et al. 2007), the process of adsorption and desorption can vary according to the composition of natural sediments. Natural sediments cannot be considered totally free of contamination. Taking this into consideration, the use of a chemically-spiked artificial sediment is a solution that could allow the standardization of assays for hydrophobic pollutant testing. While an artificial sediment is already available for chemical testing on chironomids (OECD 2004), it is not suitable for fish development. Its elevated clay content $(20 \% \mathrm{dw})$ may clog the chorion of embryos and thus prevent gas exchanges and impair embryonic development.

This study aims to develop and validate a new reference artificial sediment for toxicity testing of hydrophobic chemicals using the MELA sediment contact assay. The first step was to form the artificial sediment from three components: sand, clay, and organic matter. This was then tested using fluoranthene (fluo). Three consecutive experiments were performed to select a suitable grain size for sand and organic matter based on three criteria: maximal fluo spiking efficiency, maximal fluo toxicity, and safety of the solvent control sediment for medaka embryo development. Fluo was selected as a model pollutant for its high hydrophobicity, high absorption capacity for particles and organic matter, and common presence in the aquatic environment (Guasch et al. 2012; Cachot et al. 2006). The second step consisted of validating the final composition of the artificial sediment with several fluo concentrations, with repeated fluo exposures. This was also applied to two other model PAH compounds: benz $[a]$ anthracene $(\mathrm{BaA})$ and benzo $[a]$ pyrene $(\mathrm{BaP})$. 


\section{Materials and methods}

\subsection{Chemicals}

Sigma-Aldrich (St Quentin Fallavier, France) supplied fluoranthene fluo, benzo[a]pyrene BaP, and benz $[a]$ anthracene $\mathrm{BaA}$ as well as Ethyl 4-aminobenzoate (benzocaine). Spiking solutions of fluo at $750 \mu \mathrm{g} \mathrm{mL}$

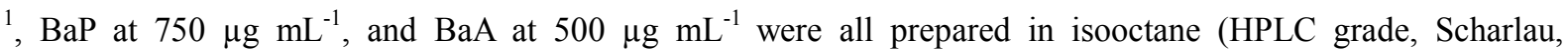

\subsection{Artificial reference sediment preparation}

Three consecutive experiments were performed to ascertain the most suitable composition for the artificial sediment, in terms of sand grain size (experiment 1A), clay content (experiment 1B), and organic matter content (experiment 1C), as illustrated in Figure 1. Three criteria were used to select the most suitable sediment composition: maximum spiking efficiency, maximal fluo toxicity, and lack of toxicity detected in the solvent control sediment. The composition and preparation of the artificial sediment were based on the OECD 218 (OECD 2004) and recent works from Nia et al. (2011) and Zielke (2011).

Experiment 1A aimed to select the size of sand grain suitable for hydrophobic compound testing with the MELAc test. Sand supplied by Sibelco (sand reference BB 0.2/2h, Mios, France) was washed once with hydrochloric acid (7\%) then rinsed generously with Milli-Q water before being used. After 24 h of drying at 90 ${ }^{\circ} \mathrm{C}$, the sand was sieved and placed into 3 categories: particles below $0.2 \mathrm{~mm}$, particles between $0.2-0.5 \mathrm{~mm}$ and particles between $0.5 \mathrm{~mm}$ and $2 \mathrm{~mm}$. The $0.2-0.5 \mathrm{~mm}$ sand fraction appeared the most suitable for chemical testing with the MELAc, and was selected to make up the artificial sediment used in our experiments.

Experiment 1B aimed to define the most suitable clay content in the artificial sediment. Kaolin clay (Merck, Darmstadt, Germany) was added to 0.2-0.5 mm sand fractions, for a final clay concentrations of 0, 7.5, 15 or $30 \% \mathrm{dw}$ in glass bottles. Sediment was moistened with Milli-Q water 1:4 v/v, mixed at $180 \mathrm{rpm}$ for $4 \mathrm{~h}$, and then dried for $24 \mathrm{~h}$ at $90{ }^{\circ} \mathrm{C}$. Clay was shown to affect hatching success during exposure, even at the lowest concentration tested, $7.5 \%$ (data not shown). Consequently, the clay content in the artificial sediment was set at $5 \%$ to avoid embryo clogging. 
Experiment $1 \mathrm{C}$ aimed to establish the most suitable organic matter content in the artificial sediment.

Sphagnum blond peat (Florentaise, St Mars du Désert, France) was dried for $48 \mathrm{~h}$, then sieved to retain only those particles below $0.5 \mathrm{~mm}$. Blond peat was moistened with Milli-Q water $(1: 25 \mathrm{v} / \mathrm{v})$, and then mixed for $48 \mathrm{~h}$ at $180 \mathrm{rpm}$. Humid peat at $0,2.5$ or $5 \% \mathrm{dw}$ final concentration was then added to $0.2-0.5 \mathrm{~mm}$ sand fraction supplemented with $5 \%$ of clay. The sediment was then mixed by continuous shaking at $180 \mathrm{rpm}$ for an additional $24 \mathrm{~h}$ period. The $\mathrm{pH}$ was then adjusted to 6.5 using calcite solution (10\% in Milli-Q water). After 7 days of storage at room temperature for stabilisation, 1:4 v/v of Milli-Q water was added to the sediment in each bottle. Supernatant water was removed after $24 \mathrm{~h}$ decantation. The sediment was then dried at $105{ }^{\circ} \mathrm{C}$ for $14 \mathrm{~h}$ without shaking. After testing, peat content in the artificial sediment was set at $2.5 \%$.

Experiments 2A, 2B, 2C and 2D aimed to validate the composition of the artificial sediment: $92.5 \%$ 0.2-0.5 mm grain size, $5 \%$ clay and $2.5 \%$ peat. The $10 \mu \mathrm{g} \mathrm{g}^{-1} \mathrm{dw}$ fluo treatment was repeated in experiments and spiked separately to perform independent statistical analyses. For experiment $2 \mathrm{~A}$, three different fluo concentrations were tested: 3,10 and $30 \mu \mathrm{g} \mathrm{g}^{-1} \mathrm{dw}$. Experiments $2 \mathrm{C}$ and $2 \mathrm{D}$ aimed to validate the artificial sediment using two other model PAHs with different Kow and thus different physico-chemical and toxicological properties. $\mathrm{BaA}$ toxicity was assessed in experiment $2 \mathrm{C}$ and $\mathrm{BaP}$ in experiment $2 \mathrm{D}$.

\subsection{Sediment spiking}

Individual PAH nominal concentration was set to $10 \mu \mathrm{g} \mathrm{g}^{-1} \mathrm{dw}$, a value previously reported for total PAHs in sediments from the upper Seine estuary (Cachot et al. 2006). For experiments 1A, 1B, 1C, and 2B the sediment was spiked only with solvent (as a control) or with $10 \mu \mathrm{g} \mathrm{g}^{-1} \mathrm{dw}$ nominal fluo concentration. For experiment $2 \mathrm{~B}$, the sediment was spiked only with solvent, or with 3,10 or $30 \mu \mathrm{g} \mathrm{g}^{-1} \mathrm{dw}$ nominal fluo concentrations. For experiments $2 \mathrm{C}$ and $2 \mathrm{D}$, the sediment was spiked only with solvent or with $10 \mu \mathrm{g} \mathrm{g}^{-1}$ of $\mathrm{BaA}$ or BaP nominal concentration. Artificial sediment $(30 \mathrm{~g} \mathrm{dw})$, dichloromethane $(60 \mathrm{~mL})$ and spiking solution were added to a $250 \mathrm{~mL}$ glass flask. Solvent was evaporated with a rotary evaporator Rotavapor (IKA, Staufen, Germany) at $115 \mathrm{rpm}, 45^{\circ} \mathrm{C}$ for 50 to $60 \mathrm{~min}$. To ensure elimination of residual solvent, spiked sediments were stored overnight in the dark at room temperature, under a fume hood (Vicquelin et al. 2011). For each spiked sediment, one sample of $5 \mathrm{~g}$ aliquots was kept for chemical analysis. Spiked sediments were stored in the dark at ambient temperature and usually used within two days. 


\subsection{Physico-chemical characterisation of the artificial sediment}

The particle-size distribution of the sediment was determined by diffractometry. Artificial reference sediment was moistened and mixed with ERS $24 \mathrm{~h}$ at $100 \mathrm{rpm}$. Pore water was then extracted from the sediment by centrifugation at $4000 \mathrm{rpm}$ for $10 \mathrm{~min}$ and stored at $-20{ }^{\circ} \mathrm{C}$ prior analysis. Dissolved ammonium in pore water was quantified using a colorimetric method (Strickland and Parsons 1972) and the particulate organic carbon concentration of the sediment by infrared spectroscopy (Etcheber et al. 1999). These three analyses were performed in triplicates.

\subsection{PAH analysis in sediment}

Sediment samples were stored at $-20{ }^{\circ} \mathrm{C}$ before analysis. Internal deuterated standards fluo d10, chrysene $\mathrm{d} 12$ and $\mathrm{BaP}$ d12 were added prior to extraction of $0.2 \mathrm{~g}$ of sediment and to one blank analysis. PAH compounds were extracted for $10 \mathrm{~min}$ at $30 \mathrm{~W}$ using microwave extraction with dichloromethane as a solvent (Budzinski et al. 2000). Samples were then re-concentrated using a Vacuum Evaporation System (Rapidvap Labconco, Kansas city, USA). Concentrated extracts were purified using alumina micro-columns and eluted with $3 \times 5 \mathrm{~mL}$ of dichloromethane. After another re-concentration step, the aliphatic fraction was eluted on a silica micro-columns using a mix of pentane/dichloromethane $(65 / 35, \mathrm{v} / \mathrm{v})$. Finally, samples were concentrated in isooctane then pyrene $\mathrm{d} 10$ and benzo[b]fluoranthene $\mathrm{d} 12$ were both added as syringe standards before injection. Fluo, $\mathrm{BaA}$ and $\mathrm{BaP}$ molecules were analysed by gas chromatography coupled to mass spectrometry (GC-MS) as described by Baumard et al. (1998). Average extraction efficiency for all compounds was generally very satisfactory, at $70.0 \pm 9.4 \%$ for fluo, $95.0 \pm 13.0 \%$ for $\mathrm{BaA}$, and $87.2 \pm 14.6 \%$ for $\mathrm{BaP}(\mathrm{mean} \pm \mathrm{SD})$. The entire analytical procedure was applied to the certified marine sediment SRM 1944 (NIST, Gaithersburg, MD, USA) with grain size, organic carbon content and PAH concentration (NIST 2008) comparable to the artificial sediment used in the present study.

\subsection{Embryo collection and exposure}

Gis-Amagen (INRA, Jouy-en-Josas, France) provided Japanese Medaka Oryzias latipes embryos (CAB strain) at early gastrula, stage 14-15 (Iwamatsu 2004). Embryos at one day post fertilisation (dpf) were put into a Nitex ${ }^{\circledR}$ thermoformed basket which was in turn placed onto the surface of the sediment. Exposure by sediment contact was performed throughout embryonic development from $1 \mathrm{dpf}$ until hatching. Exposures, replicated 3 times per condition, were carried out in $35 \mathrm{~mm}$ diameter plastic Petri dishes (Greiner, Courtaboeuf, France) 
containing $3 \mathrm{~g}$ dw of sediment, $3 \mathrm{~mL}$ of Egg Rearing Solution ERS ( $1 \mathrm{~g} \mathrm{NaCl}, 0.03 \mathrm{~g} \mathrm{KCl}, 4.04 \mathrm{~g} \mathrm{CaCl}_{2}$ and $0.163 \mathrm{MgSO}_{4}$ in $1 \mathrm{~L}$ Milli-Q autoclaved water) and 25 embryos. During exposure, the ERS medium was renewed daily. Experiments took place in a climate chamber (Snidjers Scientific, Tilburg, the Nederlands) at $26 \pm 0.3{ }^{\circ} \mathrm{C}$ with a light:dark photoperiod of 12:12, and $5000 \mathrm{~lx}$ white light. When more than half of the individuals hatched in the three replicats of a single condition, exposure was then stopped for all conditions. After hatching, prolarvae were observed and transferred into glass beaker containing $20 \mathrm{~mL}$ of mixed water (dechlorinated tap water mixed with distilled water 1:2 v/v aerated for $24 \mathrm{~h}$ ). At the end of the exposure, non-hatched embryos were transferred into new plastic Petri dishes containing $3 \mathrm{~mL}$ ERS without sediment until hatching. Three days after hatching, the experiment was stopped by euthanizing all remaining larvae and embryos with a lethal dose of 120 mg L ${ }^{-1}$ Ethyl 4-aminobenzoate. Pro-larvae were not fed during the experiment.

Dissolved oxygen concentration was measured daily before ERS renewal in each exposure unit with a fiber-optic oxygen mini-sensor Fibox 3 (PreSens Precision Sensor, Regensburg, Germany). Measurements were compensated with a temperature sensor PT 1000. After 3 min of oxygen and temperature sensor stabilisation, data was recorded using OxyView v6.02 software (PreSens Precision Sensor, Regensburg, Germany). The oxygen probe was placed at the interface between the ERS and the sediment.

\subsection{Embryo-larval assay}

Dead embryos and larvae were recorded daily and immediately removed to avoid alteration of the medium. Embryonic survival referred to the number of live embryos or hatched larvae at the end of the experiment compared to the number of embryos at $24 \mathrm{~h}$ of exposure. Embryos that died within the first $24 \mathrm{~h}$ of the test $(2$ to $5 \%$ ) were not taken into consideration for the calculation, since this was likely to be related to transportation stress. Larval survival referred to the number of larvae alive at the end of the experiment compared to the total number of hatched individuals. Hatching rate referred to the number of hatched individuals compared to number of live embryos at $24 \mathrm{~h}$. Hatching time referred to the number of days that embryos took to develop, from fertilization to hatching.

Heartbeat was recorded at room temperature $23 \pm 1{ }^{\circ} \mathrm{C}$ on $7 \mathrm{dpf}$ embryos temporarily transferred to an ERS medium to facilitate measurement. It was registered under a stereomicroscope MZ 7.5 Leica (Nanterre, France) X25 magnification coupled with a halogen cold light source Intralux 4100 (Volpi, Schlieren, Switzerland). Heartbeat was counted over 3 periods of $20 \mathrm{sec}$ for the same embryo. Values were summed to obtain beat $\min ^{-1}$ data for each embryo. Five individuals were analysed per replicate. 
At hatching, 15 larvae per replicate were individually examined to record morphological abnormalities

and lesions. Observed larvae were randomly selected and photographed at X25 magnification with a stereomicroscope MZ7.5 Leica coupled with a CDD camera DFP420C Leica (Nanterre, France). Five types of abnormalities and lesions were scored: oedema (yolk sac, pericardia and skeletal); spinal (scoliosis, lordosis, cyphosis and tail bud abnormalities); craniofacial (jaw and skull abnormalities); ocular (missing eye, cyclopia, hyper or dystrophies); cardiac (anaemia, haemorrhage, ventricle size, blood circulation and heart position). Abnormalities were scored using a scale of 5 points i.e. 1 point per malformation type. One larva could exhibit several abnormality types and/or several malformations of the same type (counted once). Percentage of abnormal larvae referred to the number of larvae presenting at least one abnormality in comparison to the number of observed individuals.

Head length (from terminal point of lower jaw to rear operculum), total body length (from terminal point of lower jaw to the end of caudal fin) and yolk sac area (excluding swim bladder area) were measured between 0 and $24 \mathrm{~h}$ post hatching, on 15 larvae per condition. Swim bladder swelling was also reported. These measurements were processed using Leica Microsystems software v3.8 (Nanterre, France).

\subsection{Statistical analysis}

For all experiments, each exposure condition was identically replicated 3 times. Each replicate was an independent sample and the solvent treatment was considered as a control treatment. Data is indicated as mean \pm SD. Variance homogeneity was assessed using the F-test $(\mathrm{p}<0.01)$ and each fluo contaminated sediment was compared to its respective solvent treatment with the Student's t-test $(\mathrm{p}<0.05)$. For experiment $1 \mathrm{C}$, peat toxicity was statistically analyzed for the three different peat concentrations. Normality of data distribution was tested on data residues using the Shapiro-Wilk test $(\mathrm{p}<0.01)$. Variance homogeneity was evaluated using the Levene test $(\mathrm{p}<0.05)$. In cases of homogenous variance and normalized data, Anova analysis was performed followed by a Tukey post-hoc test $(\mathrm{p}<0.05)$. In opposite case, data was analyzed using the Kruskal-Wallis non parametric test $(\mathrm{p}<0.05)$. Principal component analysis PCA (2 axis) were performed on endpoints for which significant differences were observed. Statistical analyses were performed using Statistica software v7.1 (StatSoft, MaisonsAlfort, France). Coefficients of variation were calculated to evaluate the repeatability of the exposure to fluospiked artificial sediment.

\section{Results}




\subsection{Development of an artificial sediment}

The suitable composition of artificial sediment was evaluated regarding sand grain size (1A), clay content (1B), and peat content (1C). No significant mortality was observed during experiment 1A-1C. For solvent spiked sediments, the only toxicity recorded was a significantly increased heartbeat in embryos reared onto $0.5-2 \mathrm{~mm}$ sediment fractions compared to $<0.2 \mathrm{~mm}$ or $0.2-0.5 \mathrm{~mm}$ sediment fractions $(\mathrm{p}=0.043)$. Fluo spiking efficiency reached $49 \%, 25 \%$ and $34 \%$ for $<0.2 \mathrm{~mm}, 0.2-0.5 \mathrm{~mm}$ and $0.5-2 \mathrm{~mm}$ fractions, respectively (Table 1). Fluo exposure did not significantly affect either hatching rate or larvae morphology. However, fluo exposure significantly increased embryonic heartbeats. For the $<0.2 \mathrm{~mm}$ sediment fraction, heartbeats of fluoexposed embryos were $10 \%$ higher than in control embryos (Fig. 2A). For the 0.2-0.5 mm fraction, fluoexposed larvae hatched significantly earlier than in the solvent control group $(p=0.040)$. Therefore fluo larvae were significantly smaller at hatching $(\mathrm{p}=0.004)$. Time to hatch and total larvae length were respectively $6.1 \%$ and $4.3 \%$ significantly lower than in the control (Fig. 2B \& 2C). Moreover, the principal component analysis explained $76 \%$ of the variances based on four endpoints: heartbeat, total larvae length, hatching time and larval abnormality score (Fig. 2D). In this figure, the $0.2-0.5 \mathrm{~mm}$ solvent group was anti-correlated with the fluo treatment group with high normalized coefficients along the first axis of the PCA $(52.3 \%)$. Therefore the $0.2-0.5$ mm sediment fraction was selected as the most suitable fraction for artificial sediment.

Addition of clay to the sediment of up to $15 \%$ significantly increased fluo spiking efficiency from $63 \%$ to $105 \%$ (Table 1). Although there was no significant mortality (see supplementary material Table 1), the addition of $15 \%$ of clay to the solvent control tended to decrease the hatching rate by $9.5 \%$, compared to the solvent control containing $0 \%$ of clay (Fig. 3A). In contrast, larvae exposed to fluo-spiked sediment without clay hatched $0.7 \mathrm{dpf}$ later than corresponding control solvent group $(\mathrm{p}=0.046)$ (Fig. 3B). For $7.5 \%$ clay, fluo significantly decreased the hatching rate by $12 \%$. At $15 \%$ clay content, contaminated larvae were significantly longer $(+0.12 \mathrm{~mm})$ than in the corresponding control solvent group $(\mathrm{p}=0.033)$ (Fig. $3 \mathrm{C})$. Although the overall percentage of larval abnormalities was higher with added clay and fluo exposure, no significant difference was observed with the solvent group (see supplementary material, Table 1). The majority of abnormalities were spinal, recorded in $32.8 \%$ of the contaminated larvae exposed to $15 \%$-clay (see supplementary material, Table 1). The corresponding PCA highlighted $69 \%$ of variance in the four endpoints: total larvae length, heartbeats, hatching success and hatching time (Fig. 3D). The groups 0,15 and $30 \%$ of clay fluo and solvent treatment overlapped regarding axis $1(40.3 \%)$. The analysis did not reveal fluo and solvent treatment groups as being 
clearly independent for any clay concentration. Because a clay content of $7.5 \%$ and above tends to clog embryos and reduce hatching rates, clay concentration for the artificial sediment was set at $5 \%$.

Since addition of organic matter to the sediment could putatively lead to increased microbial activity and oxygen depletion in the water column, the ERS medium was renewed daily just after dissolved oxygen concentration measurement at the water-sediment interface. In fact, oxygen saturation ranged between $97.1 \%$ and $109.3 \%$ during embryo exposure without the addition of peat. For $2.5 \%$ peat, $87.5 \%$ dissolved oxygen was containing $5 \%$ peat, dissolved oxygen varied between $74.4 \%$ and $106.9 \%$. Dissolved oxygen content in the water column decreased significantly with increasing peat concentration in the artificial sediment, but mean values remained above $96.8 \%$ for all treatments (Supplementary material, Fig. 1). The addition of peat did not significantly affect embryo-larval survival or development in the control solvent group (see supplementary material Table 2). Fluo spiking efficiency yielded $63 \%$ for the no-peat sediment; $59 \%$ for $2.5 \%$ peat; and $44 \%$ for $5 \%$ peat (Table 1). No significant fluo-induced effect was observed regarding embryonic heartbeat, hatching rate, swim bladder inflation, or larva body and head lengths (see supplementary material Table 2). No significant fluo-induced effect on hatching time and yolk sac area was observed for $0 \%$ and $5 \%$ peat sediment with or without fluo exposure (Figure 4A \&4B and supplementary material, Fig. 1). For $2.5 \%$ peat sediment content, time to hatch was significantly delayed $(p=0.007)$ and the yolk sac area reduced $(p=0.005)$ following fluo exposure. Control larvae hatched at around $11 \mathrm{dpf}$, while fluo-exposed larvae hatched at $12.5 \mathrm{dpf}$. PAH contaminated larvae showed yolk sac area $25 \%$ smaller than in the solvent control larvae (Figure 4A \& 4B and supplementary material, Fig. 1). Fluo induced abnormalities for all three sediment peat contents. Both the score and the percentage of abnormal individuals were increased by fluo exposure $(p=0.017$ and $p=0.016)$ (Fig. $4 \mathrm{C}$ and supplementary material Table 2 and Fig.1). The fluo-spiked sediment with no peat induced the highest score, 10 times higher than no peat solvent-spiked sediment. The majority of fluo-induced larval abnormalities were spinal curvature, craniofacial deformities, and cardiovascular anomalies (supplementary material Table 2). Severe cardiovascular anomalies, such as heart abnormal position and blood circulation defects, were particularly noticeable for the "no peat" condition, accounting for up to $23.4 \%$ of contaminated larvae. For the different fluo treatments, spinal deformities represented between 8.9 and $33.7 \%$ of contaminated larvae, while craniofacial abnormalities were recorded in $13.3 \%$ to $28.9 \%$. Oedemas were only observed in fluo-exposed larvae but at a low frequency $(2.2 \%)$. Eye abnormalities were not observed. Average percentages of abnormal individuals were below $10 \%$ for all three control sediments. PCA featured $85.7 \%$ of 4 factor variances: hatching 
time, abnormality score, larvae length, and yolk sac area (Fig. 4D). Solvent and fluo treatments for $5 \%$ peat content overlapped along axis $1(51.4 \%)$. In contrast, fluo and solvent treatments for $2.5 \%$ peat content were clearly anti-correlated along axis 1 . For $0 \%$ peat content, fluo and solvent treatments were anti-correlated along axis 2 which represents only $34.3 \%$ of variance. Therefore the most suitable peat concentration for artificial sediment was set at $2.5 \%$.

\subsection{Physico-chemical composition of the artificial sediment}

Particle sizes of the final composition of the artificial sediment ranged between 0.2 and $0.5 \mathrm{~mm}$ with a median value of $0.271 \mathrm{~mm}$ (Table 2 ). The particulate organic carbon content was equivalent to $0.87 \%$. Dissolved ammonium in pore water reached in average $11.0 \mu \mathrm{M}$.

\subsection{Effect of several fluo concentrations}

Figure 5 presented the major significant effects observed in medaka early life stages exposed to three different fluo concentrations. A decrease in total larvae length for $30 \mu \mathrm{g} \mathrm{g}^{-1}$ fluo dw was reported but this was not significantly different from the solvent larvae length (Fig. 5A). Larva abnormalities at hatching increased with increasing fluo concentration, but the only significant changes occurred with highest tested concentration of fluo (Fig. 5B). Major abnormalities were spinal curvatures (Fig. 5C).

\subsection{Validation of the artificial sediment: Repeatability testing at a single fluo concentration}

The control solvent and $10 \mu \mathrm{g} \mathrm{g}^{-1}$ fluo dw conditions were replicated three times with three different batches of sediment (experiments 1C, 2A \& 2B). The results are summarized in Table 3. The fluo concentration in sediment from the three different experiences varied by $10 \%$, equivalent to an average of $6.068 \mu \mathrm{g} \mathrm{g}^{-1}$ fluo dw. The coefficients of variation (cv) for acute toxicity endpoints — such as embryonic and larval survival and hatching rate - were low, ranging from 1 to $6 \%$. Biometry of larvae, including body and head lengths, varied by the same amount. Yolk sac area varied up to $10 \%$ for solvent and $17 \%$ for fluo treatment. In contrast, the coefficients of variation of larval abnormalities, including score and percentage, were higher, particularly for the solvent treatment. This feature results likely from variations of embryo quality from one experiment to another.

\subsection{Validation of the artificial sediment: Testing with additional PAH compounds}


two PAHs affected embryo or larval survival at the studied concentrations (Table 4). BaA exposure significantly increased abnormalities in newly hatched larvae. The majority of BaA-induced abnormalities were spinal deformations and changes in jaw shape. BaP exposure did not induce teratogenicity, but significantly delayed hatching and increased yolk sac resorption.

\section{Discussion}

\subsection{Selection of suitable component concentrations}

The final composition of the artificial sediment was selected to enable maximal spiking efficiency, maximal pollutant toxicity and minimal toxicity of the non-spiked sediment matrix.

Neither embryonic nor larval mortality was observed at significant levels, whatever the treatment under consideration. Since only silica sand was used as a matrix to spike fluo for experiment 1A, spiking efficiencies did not exceed $50 \%$ regardless of the grain size. However, fluo exposure induced significant adverse effects on embryo development, depending on sediment grain size. Although increased fluo sand concentration was observed with the $<0.2 \mathrm{~mm}$ fraction, the effects of fluo on medaka embryos were more potent with the $0.2-0.5$ $\mathrm{mm}$ fraction. We can suppose that fluo was more bioavailable for medaka embryos with this sand fraction. Therefore the 0.2-0.5 mm grain size fraction was selected for the composition of the artificial sediment.

The addition of clay to the sediment in experiment 1B increased fluo spiking efficiency from $63 \%$ to $100 \%$. This is consistent with Fanget et al. (2002) who demonstrated efficient adsorption of pyrene, another 4ring PAH, to kaolin clay. They speculated that PAHs could form micro-crystals at the surface of the solid phase. In our study, when clay concentration reached $30 \% \mathrm{dw}$, fewer fluo molecules adsorbed onto sediment particles. We can assume that accessibility of adsorption sites for fluo may be limited by the presence of an excess of clay. Despite efficient fluo adsorption onto clay particles, few toxic effects were observed for medaka embryos and larvae. We can thus assume that in the exposure conditions performed in our study, fluo was weakly available to medaka embryos.

In the third experiment $1 \mathrm{C}$, it was shown that the addition of blond peat to the artificial sediment led to a reduction in the efficiency of fluo-spiking. These results are again consistent with those of Fanget et al. (2002) who demonstrated that humic acids attach to the surface of clay particles, which in turn reduce PAH sorption to binding sites. Organic matter is an effective sorbent for hydrophobic compounds such as PAHs (Guasch et al. 
2012). This is due to high molecular weight and high sorption surface of the organic matter, and the possibility of strong interactions through Van der Waals bonds to hydrophobic pollutants (Guasch et al. 2012). The bioavailability of PAH molecules bound to organic matter is controlled through two major mechanisms: sorption and facilitation, depending on the exposure scenario (Mayer et al. 2007; Bittner et al. 2011). PAH sorption is mainly governed by humic substances that are flexible in shape in the presence of water and act as a trap for hydrophobic molecules (Laor et al. 1998; Fanget et al. 2002). Thereby dissolved organic matter and particulate organic matter in water reduce freely dissolved PAHs (Akkanen and Kukkonen 2003; Akkanen et al. 2012; Laor et al. 1998; Fanget et al. 2002). Reduce bioavailability might explain the lower toxicity of fluo for sediments containing $5 \%$ peat compared to $2.5 \%$ peat. Penetration of hydrophobic chemicals in living organisms is limited by the aqueous unstirred boundary layer between the organism and the water column (Kwon et al. 2006). This layer acts as an efficient barrier for the diffusive transfer of most hydrophobic chemicals to living organisms. However, facilitation of transport in the presence of dissolved organic matter was also recently demonstrated (Mayer et al. 2007; Bittner et al. 2011; ter Laak et al. 2009). Dissolved organic matter can change the water solubility of PAHs (Döring and Marschner 1998; Laor et al. 1998). At high concentrations of dissolved humic substances, diffusive conductivity is increased, resulting in an increased uptake of pollutants by organisms (Döring and Marschner 1998; Laor et al. 1998). This may enhance transportation by associating with the toxic compound, its diffusion and its release into the organisms.

In conclusion, hydrophobic pollutants are able to accumulate in sediments by binding to silicates, clay and organic matter. Organic pollutants are trapped in complex structures of organic matter while binding interactions with clay and silicates may be more sustainable. Consequently, the organic matter content of sediment is thought to be one of the main factors driving hydrophobic pollutant availability. In addition, the daily ERS renewal performed to stabilised dissolved oxygen above $80 \%$ (OECD 1992), led to moderate sediment particle re-suspension during the exposure. This process could increase PAH desorption and consequently improve PAH bioavailability. Differences of toxicity reported in this study likely depend on the partitioning of pollutants between the water column and the sediment, as well as differences in spiking efficiencies.

\subsection{Validation of the final composition for our artificial sediment}

Repetition of fluo exposure revealed slight differences in development of the control individual that could be explained by two factors, variability in sediment and egg batches. Since the spiking efficiency of the three fractions tested was comparable, major variability observed may be due to differences in egg batch quality. 
Variability in egg quality may lead to differences in embryonic and larval survival, hatching success, larvae abnormalities, time to hatch and biometry. Coefficients of variation were acceptable, equivalent on average to 1$10 \%$, except for larval abnormalities in the control solvent. Exposition to the artificial sediment can therefore be considered reproducible if the eggs are of high quality.

A dose-dependent increase in developmental defects (mainly larval abnormalities and reduction of body length) was observed following medaka embryo exposure to fluo-spiked sediment. Exposure to BaA and BaPspiked sediments also led to adverse effects on medaka embryo development. BaP was shown to delay hatching but had low teratogenic effects in medaka embryos. In contrast, $\mathrm{BaA}$ as well as fluo had no effect on the kinetic of embryonic development but conversely induced a high level of larval abnormalities. Our findings support those of Incardona et al. for PAH embryotoxicity (Incardona et al. 2004; 2005; 2006; 2011). In our study, fluo induced more severe cardio-vascular abnormalities than $\mathrm{BaP}$, such as abnormal heart location and blood circulation defects. After waterborne exposure of zebrafish larvae to fluo but not to BaP, Matson et al. (2008) observed increased prevalence of cardiac, peri-cardiac dysfunctions and severe lordosis. BaP bioavailability may be limited by its weak solubility and high molecular weight. It can also be hypothesised that the size of the molecule may limit its penetration through the chorion. BaA, known as a strong AhR agonist (Incardona et al. 2006; Barron et al. 2004), was shown in the present study to induce developmental abnormalities such as lordosis, scoliosis and craniofacial deformities but no significant cardiac dysfunction. $\mathrm{BaP}$ is also an $\mathrm{AhR}$ agonist (Incardona et al. 2011) but appeared in our study to be less teratogenic than $\mathrm{BaA}$ or fluo. This can be partly explained by the higher soil-water partition coefficient of $\mathrm{BaP}$ ( $\log \mathrm{Koc}=5.7-6.7)$, leading to stronger adsorption to sediment particles than fluo $(\log \mathrm{Koc}=4.6-4.7)$ or $\mathrm{BaA}(\log \mathrm{Koc}=5.3)$ (Sverdrup et al. 2002; ATSDR 1995). In our bioassay conditions, fluo or BaA molecules were certainly more bioavailable than BaP for Japanese medaka embryos, resulting in higher exposure and toxicity levels. Our results suggest that PAH toxicity in Japanese medaka early life stages was related to the physico-chemical properties of the compounds tested. It was shown herein that increasing the log Koc results in decreasing PAH embryotoxicity.

\section{Conclusion}

The final sediment composition includes $92.5 \% \mathrm{dw}$ of $0.2-0.5 \mathrm{~mm}$ silica, $5 \%$ dw clay and $2.5 \% \mathrm{dw}$ Sphagnum blond peat. This artificial matrix is suitable for medaka embryo development, and allows relatively high and reproducible sorption of PAHs of different molecular weights and hydrophobicity. The developmental toxicity of moderate concentrations of three different PAHs was evidenced using this artificial sediment and the 
417 MELAc test. To fully validate this new artificial matrix, other hydrophobic organic pollutants and complex pollutant mixtures should be tested.

\section{Acknowledgments}

This study was funded by the French National Agency for Research, program "Contaminant, Ecosystème et Santé", as part of the ConPhyPoP (2009-002) research project. This work was part of the LABEX COTE cluster of excellence for continental and coastal ecosystems. Florane Le Bihanic received a PhD fellowship from the Ministère de l'Enseignement Supérieur et de la Recherche. Prescilla Perrichon received a PhD fellowship from the Conseil Général de Charente Maritime and Institut Français de Recherche pour l'Exploitation de la Mer. The authors wish to thank Steffen Keiter and Hanno Zielke for their discussion on sediment preparation and the Sibelco Company for generously providing sand. The authors would like to thanks reviewers for the deep and accurate revision of our manuscript.

\section{References}

Akkanen J, Kukkonen JVK (2003) Measuring the bioavailability of two hydrophobic organic compounds in the presence of dissolved organic matter. Environ Toxicol Chem 22 (3):518-524.

Akkanen J, Tuikka A, Kukkonen JVK (2012) On the borderline of dissolved and particulate organic matter: Partitioning and bioavailability of polycyclic aromatic hydrocarbons. Ecotoxicol Environ Saf 78:91-98

ATSDR (1995) Toxicological profile for polycyclic aromatic hydrocarbons. U.S. Department of Health and Human Services, Public Health Service, Atlanta, GA

Barjhoux I, Baudrimont M, Morin B, Landi L, Gonzalez P, Cachot J (2012) Effects of copper and cadmium spiked-sediments on embryonic development of Japanese medaka (Oryzias latipes). Ecotoxicol Environ Saf 79:272-282

Barron MG, Heintz R, Rice SD (2004) Relative potency of PAHs and heterocycles as aryl hydrocarbon receptor agonists in fish. Mar Environ Res 58 (2-5):95-100

Baumard P, Budzinski H, Garrigues P (1998) PAHs in Arcachon Bay, France: Origin and biomonitoring with caged organisms. Mar Pollut Bull 36 (8):577-586.

Baumard P, Budzinski H, Garrigues P, Narbonne JF, Burgeot T, Michel X, Bellocq J (1999) Polycyclic aromatic hydrocarbon (PAH) burden of mussels (Mytilus sp.) in different marine environments in relation with sediment PAH contamination, and bioavailability. Mar Environ Res 47 (5):415-439 
Belanger SE, Balon EK, Rawlings JM (2010) Saltatory ontogeny of fishes and sensitive early life stages for ecotoxicology tests. Aquat Toxicol 97 (2):88-95

Benlahcen KT, Chaoui A, Budzinski H, Bellocq J, Garrigues P (1997) Distribution and sources of polycyclic aromatic hydrocarbons in some Mediterranean coastal sediments. Mar Pollut Bull 34 (5):298-305

Bittner M, Macikova P, Giesy JP, Hilscherova K (2011) Enhancement of AhR-mediated activity of selected pollutants and their mixtures after interaction with dissolved organic matter. Environ Int 37 (5):960-964

Bouloubassi I, Méjanelle L, Pete R, Fillaux J, Lorre A, Point V (2006) PAH transport by sinking particles in the open Mediterranean Sea: A 1 year sediment trap study. Mar Pollut Bull 52 (5):560-571

Budzinski H, Letellier M, Thompson S, Le Menach K, Garrigues P (2000) Combined protocol for the analysis of polycyclic aromatic hydrocarbons (PAHs) and polychlorobiphenyls (PCBs) from sediments using focussed microwave assisted (FMW) extraction at atmospheric pressure. Fresenius J Anal Chem 367 (2):165-171.

Cachot J, Geffard O, Augagneur S, Lacroix S, Le Menach K, Peluhet L, Couteau J, Denier X, Devier MH, Pottier D, Budzinski H (2006) Evidence of genotoxicity related to high PAH content of sediments in the upper part of the Seine estuary (Normandy, France). Aquat Toxicol 79 (3):257-267

Cachot J, Law M, Pottier D, Peluhet L, Norris M, Budzinski H, Winn R (2007) Characterization of toxic effects of sediment-associated organic pollutants using the $\lambda$ transgenic medaka. Environ Sci Technol 41 (22):7830-7836

Cachot J, Minier C, Law M, Didier PC, Schleis J, Peluhet L, Norris M, Budzinski H, Winn R (2008) The use of embryos of the Lambda $c I I$ transgenic medaka to assess short and long term effects of sediment-sorbed pollutants: Application to sediments of the Seine estuary (Normandy, France). Mar Environ Res 66 (1):65-65

Cailleaud K, Forget-Leray J, Peluhet L, LeMenach K, Souissi S, Budzinski H (2009) Tidal influence on the distribution of hydrophobic organic contaminants in the Seine Estuary and biomarker responses on the copepod Eurytemora affinis. Environ Pollut 157 (1):64-71

Cailleaud K, Forget-Leray J, Souissi S, Lardy S, Augagneur S, Budzinski H (2007) Seasonal variation of hydrophobic organic contaminant concentrations in the water-column of the Seine Estuary and their transfer to a planktonic species Eurytemora affinis (Calanoïd, copepod). Part 2: Alkylphenolpolyethoxylates. Chemosphere 70 (2):281-287 
Döring UM, Marschner B (1998) Water solubility enhancement of benzo(a)pyrene and 2,2',5,5'terachlorobiphenyl by dissolved organic matter (DOM). Physics and Chemistry of the Earth 23 (2):193197

EC (2000) Directive 2000/60/EC of the European parliament and of the council of 23 October 2000 establishing a framework for Community action in the field of water policy. vol L 327. Official Journal of the European Union,

EC (2006) Regulation (EC) $\mathrm{N}^{\circ} 1907 / 2006$ of the european parliament and of the concil concerning the Registration Evaluation and Authorization of Chemicals (REACh). vol L 396. Official Journal of the European Union,

EC (2010) Directive 2010/63/EU of the european parliament and of the council of 22 September 2010 on the protection of animals used for scientific purposes. vol L276. Official Journal of the European Union.

Embry MR, Belanger SE, Braunbeck TA, Galay-Burgos M, Halder M, Hinton DE, Léonard MA, Lillicrap A, Norberg-King T, Whale G (2010) The fish embryo toxicity test as an animal alternative method in hazard and risk assessment and scientific research. Aquat Toxicol 97 (2):79-87

Etcheber H, Relexans J-C, Beliard M, Weber O, Buscail R, Heussner S (1999) Distribution and quality of sedimentary organic matter on the Aquitanian margin (Bay of Biscay). Deep Sea Research Part II: Topical Studies in Oceanography 46 (10):2249-2288

Fanget B, Devos O, Naffrechoux E (2002) Pyrene transfer from clay particles to water: the role of humic acid. Rev Sci Eau 15:95-108

Farwell A, Nero V, Croft M, Bal P, Dixon DG (2006) Modified Japanese medaka embryo-larval bioassay for rapid determination of developmental abnormalities. Arch Environ Contam Toxicol 51 (4):600-607

Guasch H, Ginebreda A, Geiszinger A, Akkanen J, Slootweg T, Mäenpää K, Leppänen M, Agbo S, Gallampois C, Kukkonen JK (2012) Bioavailability of organic contaminants in freshwater environments. In: Emerging and Priority Pollutants in Rivers. The Handbook of Environmental Chemistry. Springer Berlin Heidelberg, pp 25-53.

Harris JRW, Cleary JJ, Valkirs AO (1996) Particle-Water Partitioning and the Role of Sediments as a Sink and Secondary Source of TBT. In: Champ MA, Seligman PF (eds) Organotin. Springer Netherlands, pp 459-473.

Hollert H, Keiter S, König N, Rudolf M, Ulrich M, Braunbeck T (2003) A new sediment contact assay to assess particle-bound pollutants using zebrafish (Danio rerio) embryos. J Soils Sed 3 (3):197-207. 
Hornung MW, Cook PM, Flynn KM, Lothenbach DB, Johnson RD, Nichols JW (2004) Use of multi-photon laser-scanning microscopy to describe the distribution of xenobiotic chemicals in fish early life stages. Aquat Toxicol 67 (1):1-11

Höss S, Ahlf W, Fahnenstich C, Gilberg D, Hollert H, Melbye K, Meller M, Hammers-Wirtz M, Heininger P, Neumann-Hensel H, Ottermanns R, Ratte HT, Seiler TB, Spira D, Weber J, Feiler U (2010) Variability of sediment-contact tests in freshwater sediments with low-level anthropogenic contamination Determination of toxicity thresholds. Environ Pollut 158 (9):2999-3010

Hsu P, Matthäi A, Heise S, Ahlf W (2007) Seasonal variation of sediment toxicity in the Rivers Dommel and Elbe. Environ Pollut 148 (3):817-823

Incardona JP, Carls MG, Teraoka H, Sloan CA, Collier TK, Scholz NL (2005) Aryl hydrocarbon receptorindependent toxicity of weathered crude oil during fish development. Environ Health Perspect 113 (12): $1755-1762$

Incardona JP, Collier TK, Scholz NL (2004) Defects in cardiac function precede morphological abnormalities in fish embryos exposed to polycyclic aromatic hydrocarbons. Toxicol Appl Pharmacol 196 (2):191-205

Incardona JP, Day HL, Collier TK, Scholz NL (2006) Developmental toxicity of 4-ring polycyclic aromatic hydrocarbons in zebrafish is differentially dependent on $\mathrm{AH}$ receptor isoforms and hepatic cytochrome P4501A metabolism. Toxicol Appl Pharmacol 217 (3):308-321

Incardona JP, Linbo TL, Scholz NL (2011) Cardiac toxicity of 5-ring polycyclic aromatic hydrocarbons is differentially dependent on the aryl hydrocarbon receptor 2 isoform during zebrafish development. Toxicol Appl Pharmacol 257 (2):242-249

Iwamatsu T (2004) Stages of normal development in the medaka Oryzias latipes. Mech Dev 121 (7-8):605-618

Kosmehl T, Hallare AV, Reifferscheid G, Manz W, Braunbeck T, Hollert H (2006) A novel contact assay for testing genotoxicity of chemicals and whole sediments in zebrafish embryos. Environ Toxicol Chem 25 (8):2097-2106. doi:10.1897/05-460r.1

Kwon JH, Katz LE, Liljestrand HM (2006) Use of a parallel artificial membrane system to evaluate passive absorption and elimination in small fish. Environ Toxicol Chem 25 :3083-3092.

Lammer E, Carr GJ, Wendler K, Rawlings JM, Belanger SE, Braunbeck T (2009) Is the fish embryo toxicity test (FET) with the zebrafish (Danio rerio) a potential alternative for the fish acute toxicity test? Comparative Biochemistry and Physiology Part C: Toxicology \& Pharmacology 149 (2):196-209 
Laor Y, Farmer WJ, Aochi Y, Strom PF (1998) Phenanthrene binding and sorption to dissolved and to mineralassociated humic acid. Water Res 32 (6):1923-1931

Matson CW, Timme-Laragy AR, Di Giulio RT (2008) Fluoranthene, but not benzo[a]pyrene, interacts with hypoxia resulting in pericardial effusion and lordosis in developing zebrafish. Chemosphere 74 (1):149154

Mayer P, Fernqvist MM, Christensen PS, Karlson U, Trapp S (2007) Enhanced Diffusion of Polycyclic Aromatic Hydrocarbons in Artificial and Natural Aqueous Solutions. Environ Sci Technol 41 (17):6148-6155.

McElroy AE, Bogler A, Weisbaum D, Norris M, Mendelman LV, Setlow R, Winn R (2006) Uptake, metabolism, mutant frequencies and mutational spectra in $\lambda$ transgenic medaka embryos exposed to benzo[ $\alpha]$ pyrene dosed sediments. Mar Environ Res 62 (Supplement 1):S273-S277

Nia Y, Garnier JM, Rigaud S, Hanna K, Ciffroy P (2011) Mobility of Cd and Cu in formulated sediments coated with iron hydroxides and/or humic acids: A DGT and DGT-PROFS modeling approach. Chemosphere 85 (9):1496-1504

NIST (2008) Certificate of Analysis for Standard Reference Material (SRM)1944 New York/New Jersey Waterway Sediment, National institute of Standards and Technology (NIST), Gaithersburg (22 December 2008)

OECD (1992) Guidelines for the testing of chemicals fish early life stage toxicity test, Test No. 210. Section 2: Effects on biotic systems. Organization for Economic Cooperation and Developpment,

OECD (2004) Guidelines for the testing of chemicals sediment-water chironomid toxicity test using spiked sediment, Test No. 218. Section 2: Effects on biotic systems. Organization for Economic Cooperation and Developpment,

Roberts DA (2012) Causes and ecological effects of resuspended contaminated sediments (RCS) in marine environments. Environ Int 40 (0):230-243

Rocha PS, Bernecker C, Strecker R, Mariani CF, Pompêo MLM, Storch V, Hollert H, Braunbeck T (2011) Sediment-contact fish embryo toxicity assay with Danio rerio to assess particle-bound pollutants in the Tietê River Basin (São Paulo, Brazil). Ecotoxicol Environ Saf 74 (7):1951-1959

Strickland JDH, Parsons TR (1972) A practical handbook of seawater analysis, vol 167. Fisheries Research Board of Canada Bulletin, 
Sundberg H, Hanson M, Liewenborg B, Zebühr Y, Broman D, Balk L (2007) Dredging Associated Effects: Maternally Transferred Pollutants and DNA Adducts in Feral Fish. Environ Sci Technol 41 (8):29722977.

Sverdrup LE, Nielsen T, Henning Krogh P (2002) Soil Ecotoxicity of Polycyclic Aromatic Hydrocarbons in Relation to Soil Sorption, Lipophilicity, and Water Solubility. Environmental Science and Technology $36(2429-2435)$

ter Laak TL, ter Bekke MA, Hermens JLM (2009) Dissolved organic matter enhances transport of PAHs to aquatic organisms. Environ Sci Technol 43 (19):7212-7217.

Vicquelin L, Leray-Forget J1, Peluhet L, LeMenach K, Deflandre B, Anschutz P, Etcheber H, Morin B, Budzinski H, Cachot J (2011) A new spiked sediment assay using embryos of the Japanese medaka specifically designed for a reliable toxicity assessment of hydrophobic chemicals. Aquat Toxicol 105 (3-4):235-245

Wölz J, Engwall M, Maletz S, Olsman Takner H, van Bavel B, Kammann U, Klempt M, Weber R, Braunbeck T, Hollert H (2008) Changes in toxicity and Ah receptor agonist activity of suspended particulate matter during flood events at the rivers Neckar and Rhine — a mass balance approach using in vitro methods and chemical analysis. Environ Sci Pollut Res 15 (7):536-553.

Zielke H (2011) Time-related alterations and other confounding factors in direct sediment contact tests. RWTH Aachen

\section{Figure captions:}

Fig.1: Outlines of the different series of experiments carried out for the development and validation of an artificial reference sediment specifically designed for the Medaka Embryo-Larval Assay in sediment-contact (MELAc).

Fig.2: How particles size affects fluo toxicity in Japanese medaka embryos and larvae (Experiment 1A). A) Heartbeat measured at embryonic stage $7 \mathrm{dpf}$. B) Time to hatch. C) Total length of the larvae at hatching. Different letters stand for significant differences with solvent treatment (Mean $\pm S D, N=3$, Student's t-test, $p<$ 0.05). D) Principal component analysis representing normalized coefficients on the first two axes for 4 endpoints 
(total larvae length, heartbeat, abnormality score, and time to hatch). Different numbers refer to different replicates of treatment. Plain lines refer to solvent treatments and dotted lines to fluo treatments.

Fig.3: How clay content affects fluo toxicity in Japanese medaka embryos and larvae (Experiment 1B). A) Hatching rate. B) Time to hatch. C) Total length of the larvae at hatching. Different letters stand for significant differences with solvent treatment (Mean $\pm \mathrm{SD}, \mathrm{N}=3$, Student's t-test, $\mathrm{p}<0.05$ ). D) Principal component analysis representing normalized coefficients on the first two axes for 4 endpoints (total larvae length, heartbeats, hatching rate, and time to hatch). Different numbers refer to different replicates of treatment. Plain lines refer to solvent treatments and dotted lines to fluo treatments.

Fig.4: Fluo toxicity in Japanese medaka embryos and larvae for different peat sediment content (Experiment 1C). A) Time to hatch. B) Yolk sac area. C) Larval abnormalities score at hatching. Different letters stand for significant differences with solvent treatment (Mean $\pm \mathrm{SD}, \mathrm{N}=3$, Student's t-test, $\mathrm{p}<0.05$ ). D) Principal component analysis representing normalized coefficients on the first two axes for 4 endpoints (total larvae length, hatching rate, yolk sac area, and larval abnormality score). Different numbers refer to different replicates of treatment. Plain lines refer to solvent treatments and dotted lines to fluo treatments.

Fig.5: Developmental effects on Japanese medaka exposed to different fluo concentrations (Experiment 2A). A) Total larvae length. B) Larval abnormality score. C) Spinal abnormalities. Different letters stand for significant differences within treatments (Mean $\pm \mathrm{SD}, \mathrm{N}=3$, Anova, $\mathrm{p}<0.05$ ). 
1. Development of an artificial sediment

Exp 1A : selection of suitable grain size<smiles>C=CC</smiles>

Exp 1B : selection of suitable clay content

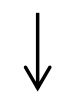

Exp 1C : selection of suitable organic matter content

2. Validation of the artificial sediment final composition

Exp 2A : dose-effects with several fluo concentrations

Exp 2B : repeatability of the condition fluo at $10 \mu \mathrm{g} \mathrm{g}^{-1} \mathrm{dw}$

Exp $2 \mathrm{C}$ : testing with $\mathrm{BaA}$ at $10 \mu \mathrm{g} \mathrm{g}^{-1} \mathrm{dw}$

Exp 2D : testing with $\mathrm{BaP}$ at $10 \mu \mathrm{g} \mathrm{g}^{-1} \mathrm{dw}$ 


\section{Figure 2}

A

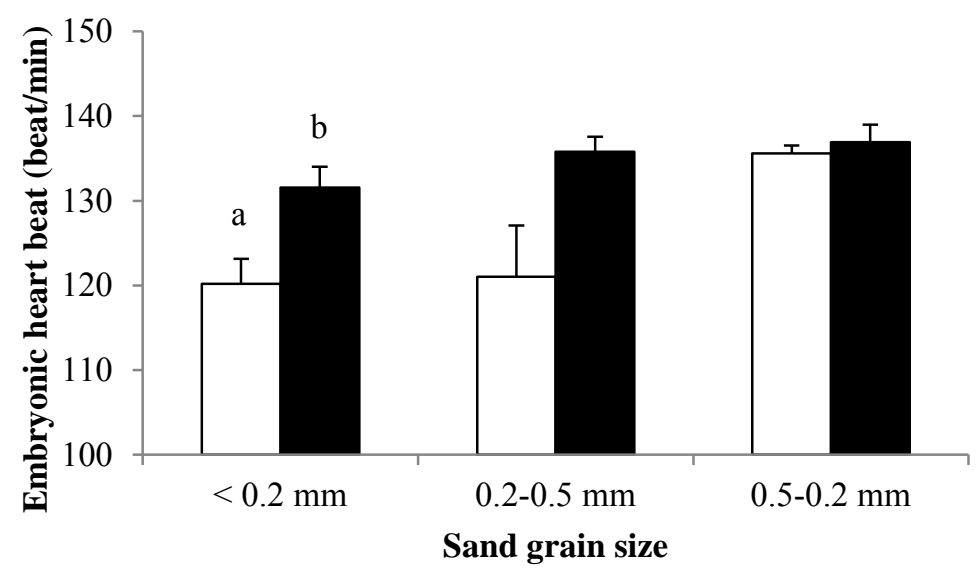

C

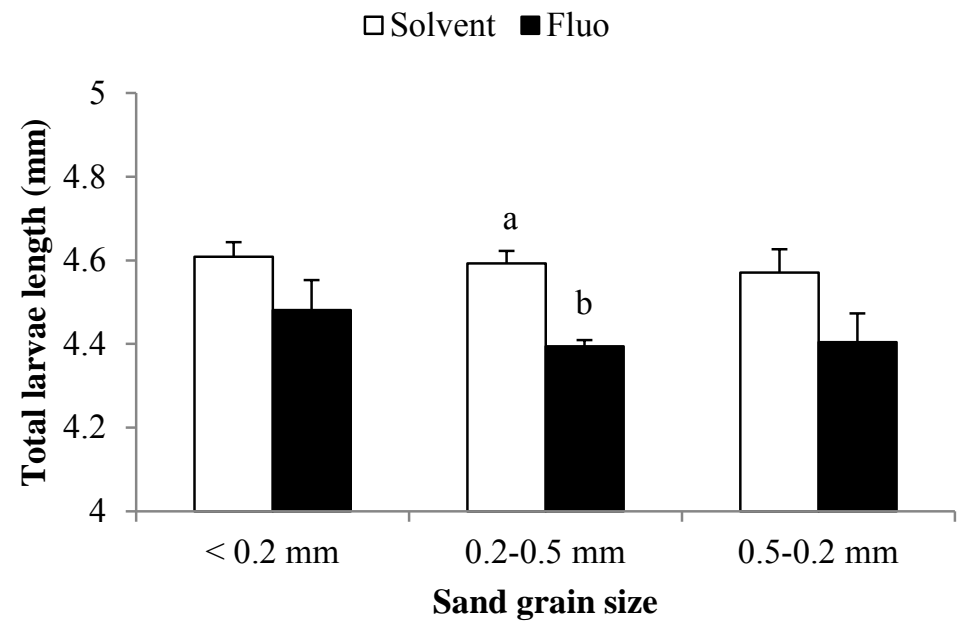

B
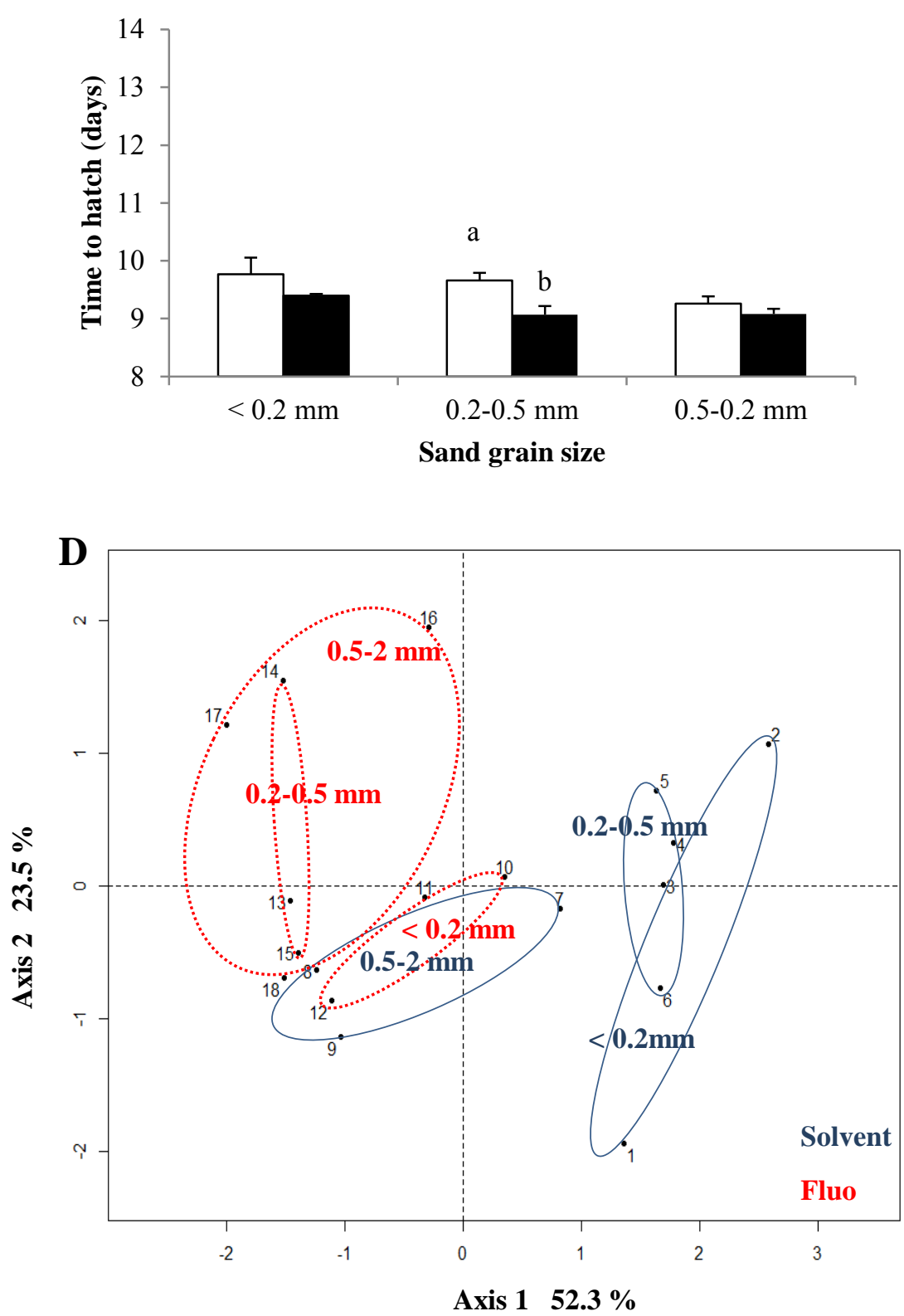


\section{Figure 3}

A

$\square$ Solvent $\square$ Fluo

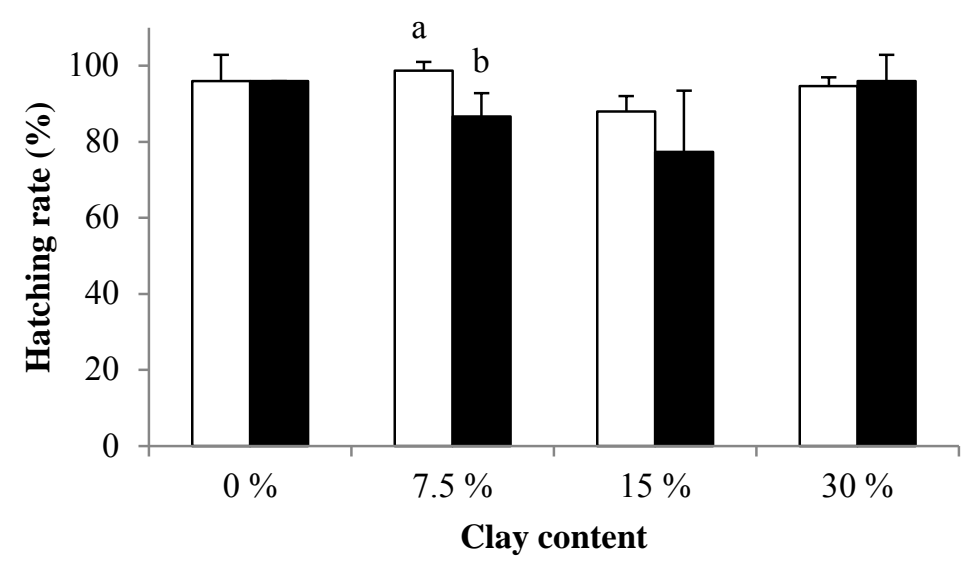

C

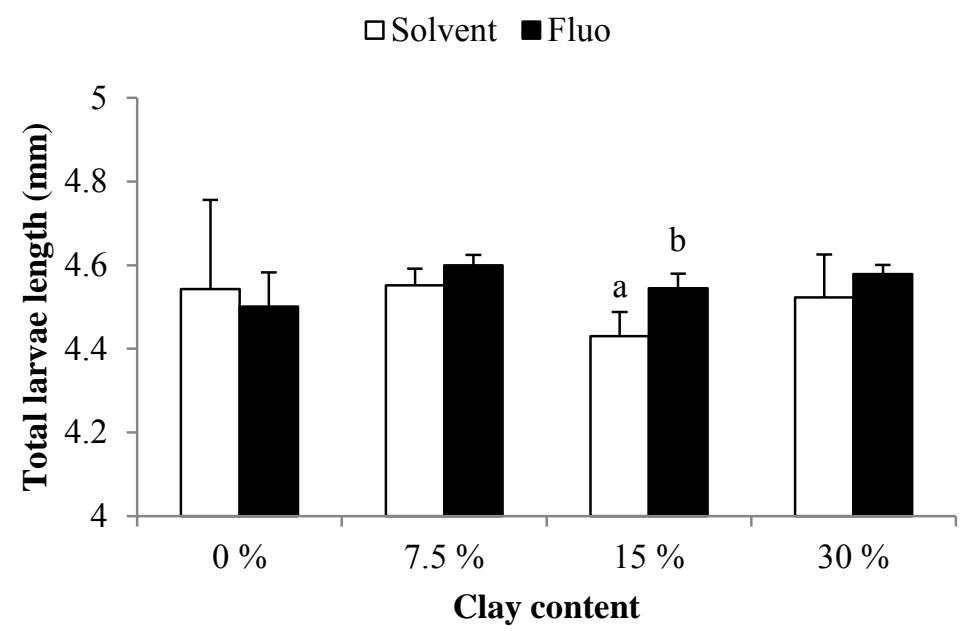

B

$\square$ Solvent $\square$ Fluo

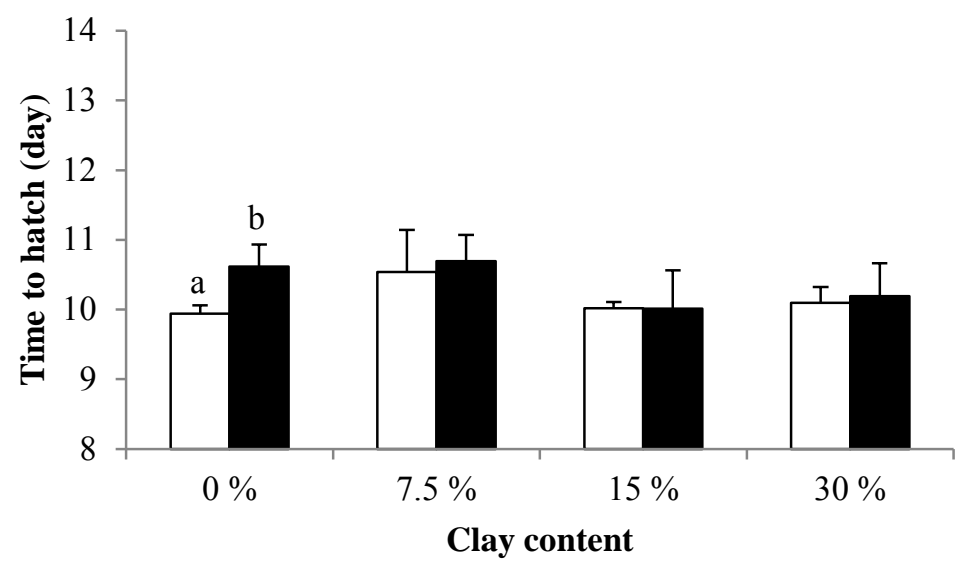

D

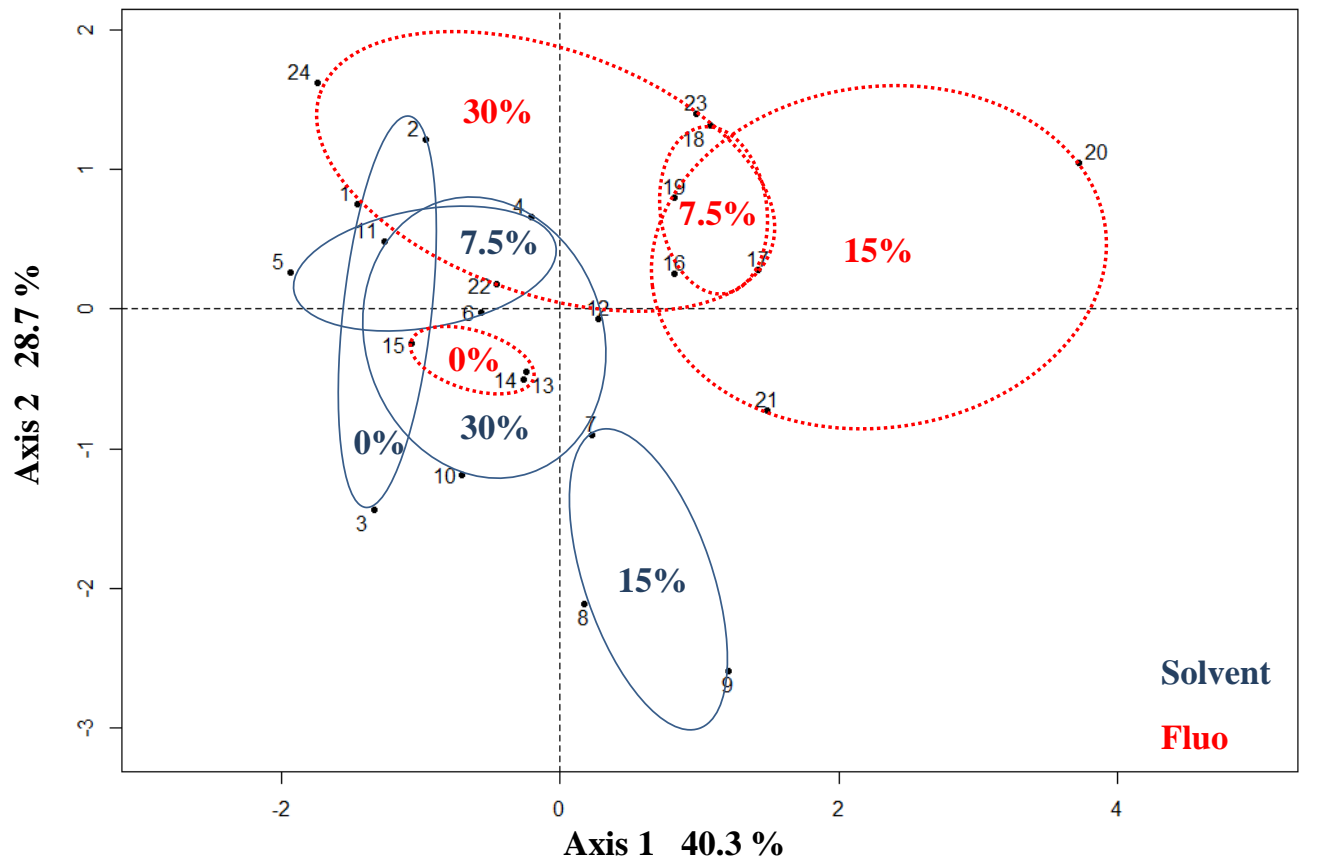


Figure 4

A

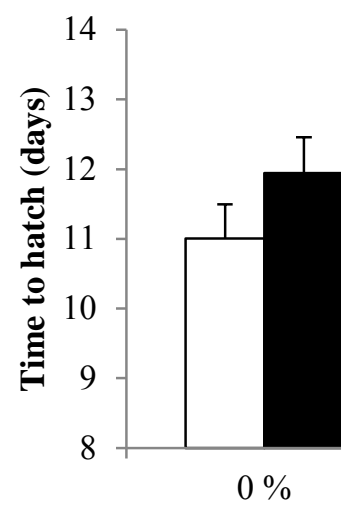

C

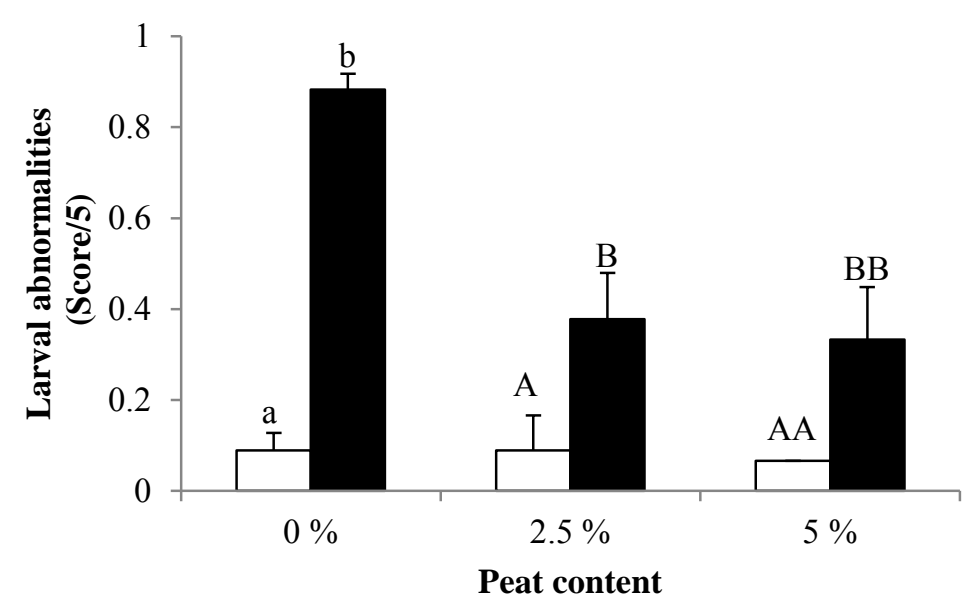

B

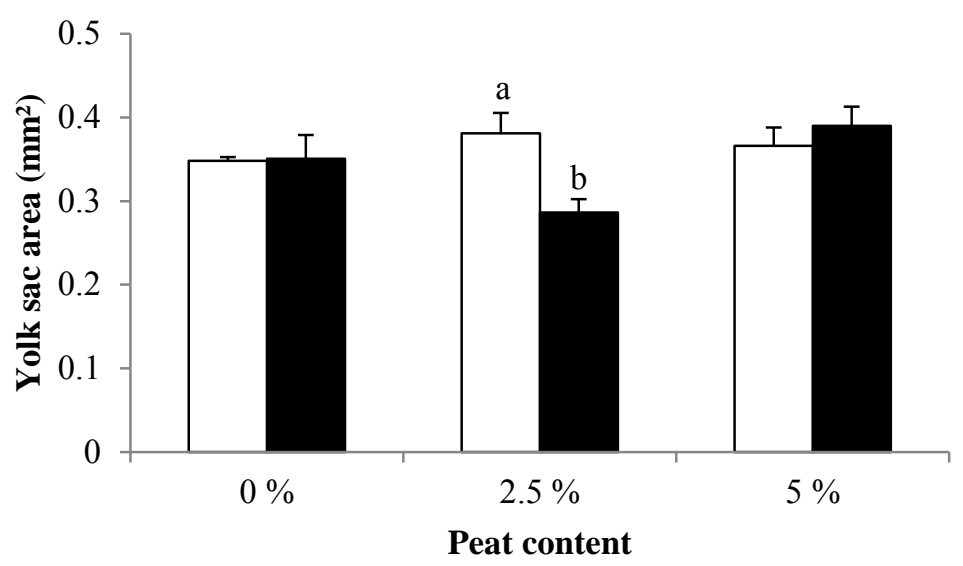

D

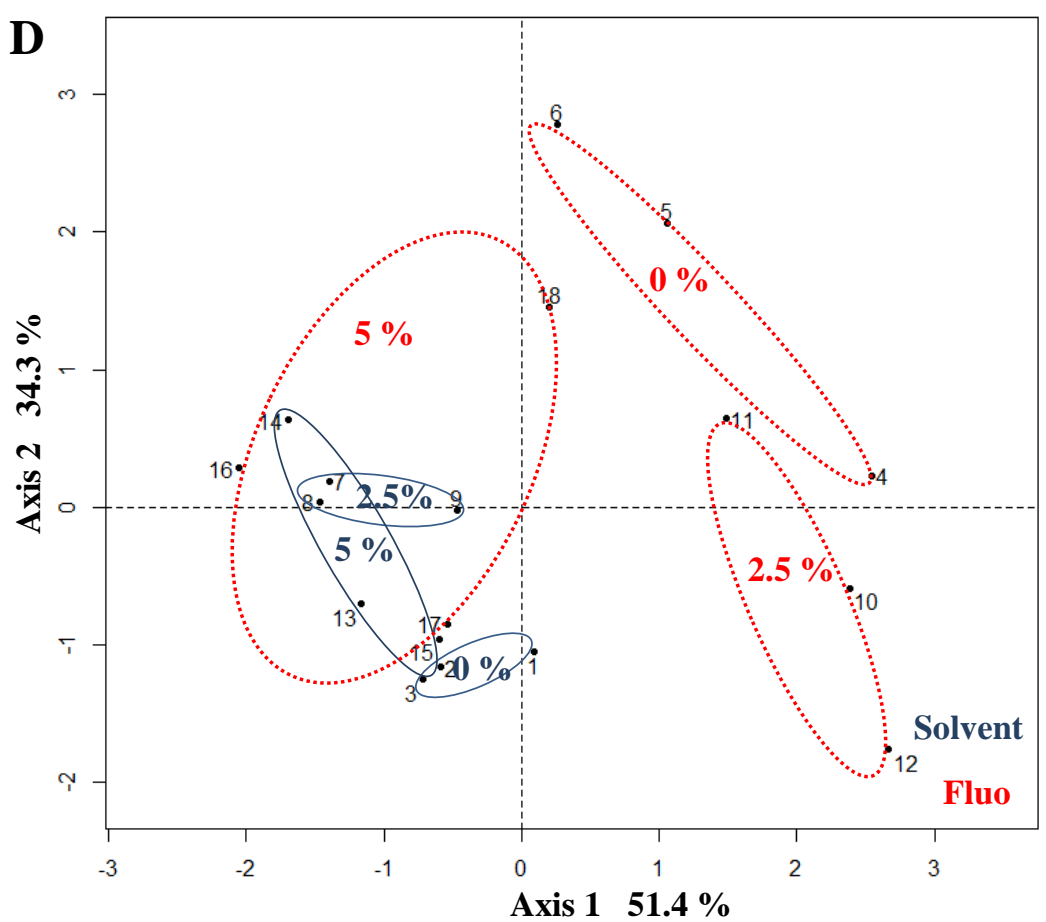




\section{Figure 5}
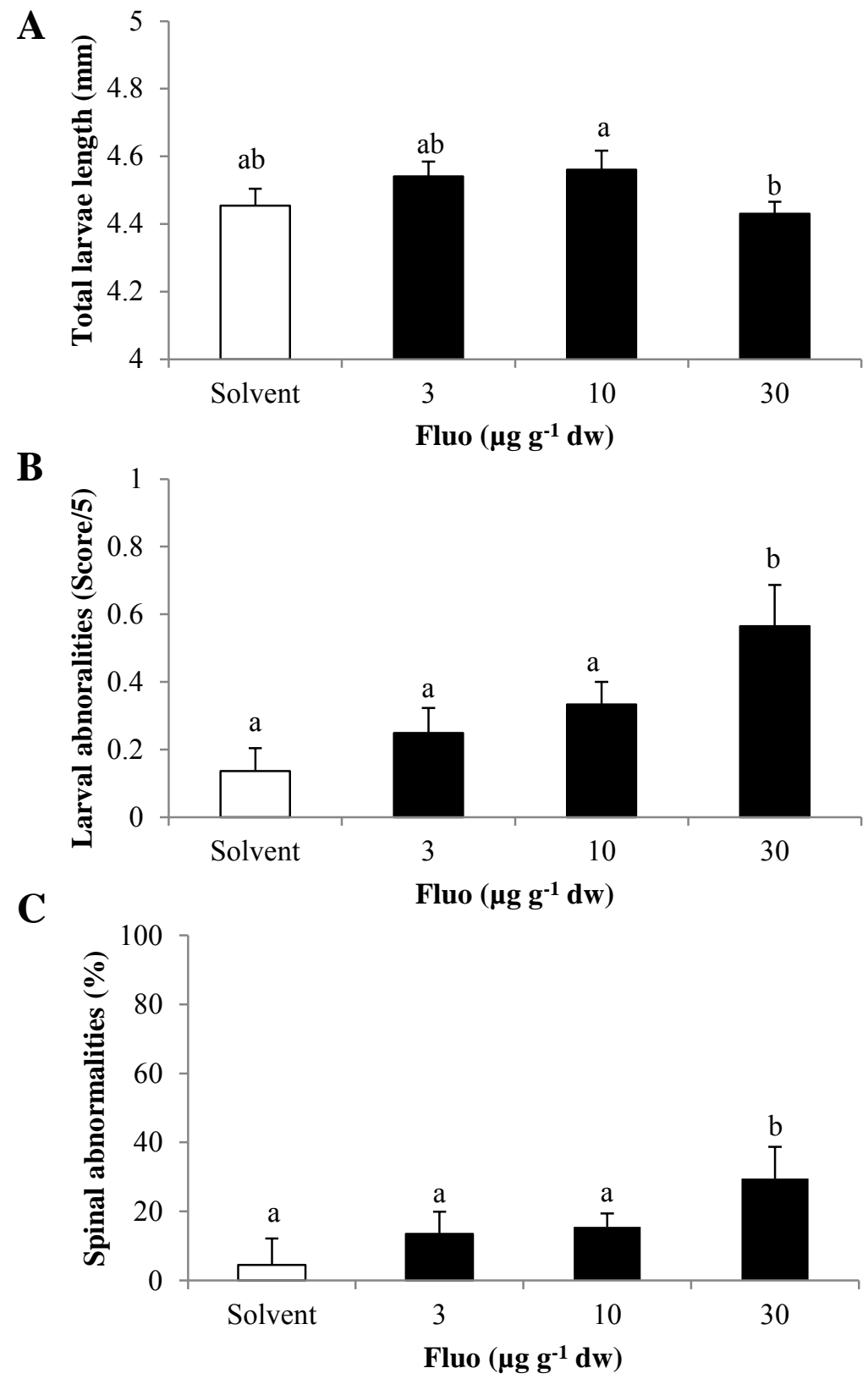
Table 1. Measured PAH concentrations in spiked sediments $(\mathrm{N}=1)$.

\begin{tabular}{|c|c|c|c|c|c|c|c|c|}
\hline \multirow{3}{*}{ Experiment } & \multicolumn{3}{|c|}{ Sediment composition } & \multicolumn{4}{|c|}{ PAH sediment concentration $\left(\mu \mathrm{g} \mathrm{g}^{-1}\right)$} & \multirow{3}{*}{$\begin{array}{l}\text { Spiking } \\
\text { efficiency }(\%)\end{array}$} \\
\hline & \multirow{2}{*}{$\begin{array}{l}\text { Grain size } \\
(\mathrm{mm})\end{array}$} & \multirow{3}{*}{$\begin{array}{l}\text { Clay } \\
(\% \text { dw })\end{array}$} & \multirow{2}{*}{$\begin{array}{l}\text { Peat } \\
(\% \text { dw })\end{array}$} & \multirow{2}{*}{$\begin{array}{l}\text { Target } \\
\text { concentration }\end{array}$} & \multicolumn{3}{|c|}{ Measured } & \\
\hline & & & & & Fluo & $\mathbf{B a A}$ & BaP & \\
\hline \multicolumn{8}{|c|}{ 1. Setting of sediment components } & \\
\hline \multirow[t]{6}{*}{$\mathbf{1 A}$} & $<0.2$ & - & - & 0 & nd & & & - \\
\hline & & & & 10 & 4.922 & & & 49 \\
\hline & $0.2-0.5$ & - & - & 0 & nd & & & - \\
\hline & & & & 10 & 2.538 & & & 25 \\
\hline & $0.5-2$ & - & - & 0 & nd & & & - \\
\hline & & & & 10 & 3.443 & & & 34 \\
\hline \multirow[t]{8}{*}{ 1B } & $0.2-0.5$ & 0 & - & 0 & 0.001 & & & - \\
\hline & & & & 10 & 6.277 & & & 63 \\
\hline & $0.2-0.5$ & 7.5 & - & 0 & nd & & & - \\
\hline & & & & 10 & 11.033 & & & 110 \\
\hline & $0.2-0.5$ & 15 & - & 0 & 0.008 & & & - \\
\hline & & & & 10 & 10.511 & & & 105 \\
\hline & $0.2-0.5$ & 30 & - & 0 & 0.009 & & & - \\
\hline & & & & 10 & 5.015 & & & 50 \\
\hline \multirow{6}{*}{$1 \mathrm{C}$} & $0.2-0.5$ & 5 & 0 & 0 & nd & & & - \\
\hline & & & & 10 & 6.321 & & & 63 \\
\hline & $0.2-0.5$ & 5 & 2.5 & 0 & nd & & & - \\
\hline & & & & 10 & 5.912 & & & 59 \\
\hline & $0.2-0.5$ & 5 & 5 & 0 & nd & & & - \\
\hline & & & & 10 & 4.396 & & & 44 \\
\hline 2. Sedi & & & & & & & & \\
\hline \multirow[t]{4}{*}{$\mathbf{2 A}$} & $0.2-0.5$ & 5 & 2.5 & 0 & nd & & & - \\
\hline & & & & 3 & 1.890 & & & 63 \\
\hline & & & & 10 & 5.563 & & & 56 \\
\hline & & & & 30 & 12.022 & & & 40 \\
\hline \multirow[t]{2}{*}{ 2B } & $0.2-0.5$ & 5 & 2.5 & 0 & nd & & & - \\
\hline & & & & 10 & 6.728 & & & 67 \\
\hline \multirow[t]{2}{*}{$2 \mathrm{C}$} & $0.2-0.5$ & 5 & 2.5 & 0 & & nd & & - \\
\hline & & & & 10 & & 5.082 & & 51 \\
\hline \multirow[t]{2}{*}{ 2D } & $0.2-0.5$ & 5 & 2.5 & 0 & & & nd & - \\
\hline & & & & 10 & & & 1.736 & 18 \\
\hline
\end{tabular}


Table 2. Physico-chemical characteristics of the final artificial sediment $(\mathrm{N}=3)$.

\begin{tabular}{|c|c|c|c|c|c|}
\hline $\mathrm{D}(\mathrm{v}, \mathbf{0 . 1 0}) \mu \mathrm{m}^{\mathrm{a}}$ & $\mathrm{D}(\mathrm{v}, \mathbf{0 . 5 0}) \boldsymbol{\mu m}$ & $\mathrm{D}(\mathrm{v}, \mathbf{0 . 9 0}) \boldsymbol{\mu m}$ & $<65 \mu \mathrm{m}(\%)$ & $\operatorname{POC}(\%)^{b}$ & $\mathbf{N}(\boldsymbol{\mu M})^{\mathbf{c}}$ \\
\hline $6.6 \pm 0.2$ & $270.9 \pm 11.1$ & $587.8 \pm 8.8$ & $30.6 \pm 1.3$ & $0.87 \pm 0.10$ & $11.0 \pm 1.7$ \\
\hline
\end{tabular}


Table 3. Repeatability of the exposures to fluo with three different batches of artificial sediment. Sediment $(0.2-0.5 \mathrm{~mm}$ sand, $5 \%$ dw clay and $2.5 \%$ peat $)$ was spiked with $10 \mu \mathrm{g} \mathrm{g}^{-1} \mathrm{dw}$ fluo. CV refers to coefficient of variation (Mean $\pm \mathrm{SD}, \mathrm{N}=3$ ).

\begin{tabular}{|c|c|c|c|c|c|c|c|c|}
\hline Treatments & & Solvent & Solvent & & Fluo & Fluo & Fluo & \\
\hline Experiment & $1 \mathrm{C}$ & $\mathbf{2 A}$ & 2B & $C V$ & $1 \mathrm{C}$ & $\mathbf{2 A}$ & $2 \mathbf{B}$ & $C V$ \\
\hline Sediment batch & 1 & 2 & 3 & & 1 & 2 & 3 & \\
\hline Fluo $\left(\mu g g^{-1} d w\right)$ & & & & & 5.912 & 5.563 & 6.728 & $10 \%$ \\
\hline [02] (\%) & $101.7 \pm 0.5$ & $94.3 \pm 1.2$ & $90.6 \pm 3.0$ & $6 \%$ & $93.1 \pm 1.1$ & $91.8 \pm 1.7$ & $92.2 \pm 1.4$ & $1 \%$ \\
\hline Embryonic survival (\%) & $96.7 \pm 5.5$ & $89.1 \pm 5.0$ & $94.5 \pm 6.4$ & $4 \%$ & $100.0 \pm 0.0$ & $90.4 \pm 2.1$ & $93.2 \pm 2.4$ & $5 \%$ \\
\hline Larval survival (\%) & $98.4 \pm 0.0$ & $100.0 \pm 0.0$ & $100.0 \pm 0.0$ & $1 \%$ & $100.0 \pm 0.0$ & $100.0 \pm 0.0$ & $98.6 \pm 2.4$ & $1 \%$ \\
\hline Hatching rate $(\%)$ & $89.2 \pm 2.5$ & $89.2 \pm 2.5$ & $93.2 \pm 4.9$ & $3 \%$ & $87.0 \pm 6.6$ & $87.7 \pm 3.8$ & $91.8 \pm 4.3$ & $3 \%$ \\
\hline Time to hatch (day) & $11.0 \pm 0.2$ & $11.8 \pm 0.2$ & $12.2 \pm 0.2$ & $5 \%$ & $12.4 \pm 0.4$ & $12.1 \pm 1.1$ & $11.6 \pm 0.4$ & $3 \%$ \\
\hline Larvae total length (mm) & $4.5 \pm 0.0$ & $4.5 \pm 0.0$ & $4.6 \pm 0.0$ & $1 \%$ & $4.5 \pm 0.1$ & $4.6 \pm 0.1$ & $4.5 \pm 0.1$ & $1 \%$ \\
\hline Larvae head length (mm) & $0.92 \pm 0.02$ & $0.84 \pm 0.02$ & $0.87 \pm 0.01$ & $5 \%$ & $0.93 \pm 0.03$ & $0.87 \pm 0.04$ & $0.83 \pm 0.02$ & $6 \%$ \\
\hline Yolk sac area $\left(\mathbf{m m}^{2}\right)$ & $0.38 \pm 0.02$ & $0.45 \pm 0.04$ & $0.38 \pm 0.01$ & $10 \%$ & $0.29 \pm 0.02$ & $0.38 \pm 0.02$ & $0.41 \pm 0.02$ & $17 \%$ \\
\hline Score of abnormalities (/5) & $0.1 \pm 0.1$ & $0.1 \pm 0.1$ & $0.3 \pm 0.1$ & $56 \%$ & $0.4 \pm 0.1$ & $0.3 \pm 0.1$ & $0.3 \pm 0.0$ & $9 \%$ \\
\hline Abnormal larvae (\%) & $8.9 \pm 7.7$ & $9.0 \pm 3.7$ & $13.3 \pm 0.0$ & $24 \%$ & $28.9 \pm 3.8$ & $24.4 \pm 7.7$ & $29.7 \pm 5.2$ & $10 \%$ \\
\hline
\end{tabular}


Table 4. Developmental effects of $\mathrm{BaP}$ - and BaA-spiked sediments on medaka embryos and larvae (Experiments $2 \mathrm{C}$ and $2 \mathrm{D})$. Values from experiments $1 \mathrm{C}$, 2A and $2 \mathrm{~B}$ were averaged. Results are expressed as induction factor relative to respective solvent control for purpose of comparison among the experiments.

Asterisks refer to statistical differences with control solvent $(\mathrm{N}=3$, Student's t-test, $\mathrm{p}<0.05)$.

\begin{tabular}{|c|c|c|c|}
\hline Endpoints & $\begin{array}{l}1 \mathrm{C}, 2 \mathrm{~A} \text { and } 2 \mathrm{~B} \\
\text { Fluo exposure }\end{array}$ & $\begin{array}{l}\mathrm{2C} \\
\text { BaA exposure }\end{array}$ & $\begin{array}{l}\mathrm{DD} \\
\text { BaP exposure }\end{array}$ \\
\hline Embryonic mortality & 1.0 & 1.1 & 1.0 \\
\hline Larval survival & 1.0 & 1.0 & 1.0 \\
\hline Hatching rate & 1.0 & 1.1 & 1.0 \\
\hline Time to hatch & 1.0 & 1.0 & $1.1^{*}$ \\
\hline Larval total length & 1.0 & 1.0 & 1.1 \\
\hline Larval head length & 1.0 & 1.0 & 1.1 \\
\hline Yolk sac area & 0.9 & 0.9 & $0.8^{*}$ \\
\hline Non-inflated swim bladder & 0.9 & 1.5 & 2.3 \\
\hline Abnormal larvae & $2.1^{*}$ & $6.5^{*}$ & 2.5 \\
\hline \multicolumn{4}{|l|}{ Abnormalities } \\
\hline Oedema & 0.5 & - & - \\
\hline Spinal & 1.8 & $7.0 *$ & 1.3 \\
\hline Craniofacial & $3.6^{*}$ & $17.8 *$ & 7.0 \\
\hline Eye & 1.0 & 3.0 & - \\
\hline Cardio-vascular & 2.2 & 4.0 & - \\
\hline
\end{tabular}


Click here to download Supplementary Material: supplementary material-Fig1.docx

Supplementary Material-Figure
Click here to download Supplem

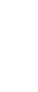

(n) 
Supplementary Material-Tables
Click here to download Supplem

Click here to download Supplementary Material: supplementary material-Tables.docx

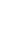

